\title{
Japanese nationwide post-marketing survey of $S-1$ in patients with advanced gastric cancer
}

\author{
Fumio Nagashima ${ }^{1}$, Atsushi Ohtsu ${ }^{1}$, Shigeaki Yoshida $^{1}$, and Kunio Ito ${ }^{2}$ \\ ${ }^{1}$ Division of Digestive Endoscopy / Gastrointestinal Oncology, National Cancer Center Hospital East, 6-5-1 Kashiwanoha, Kashiwa, \\ Chiba 277-8577, Japan \\ ${ }^{2}$ Taiho Pharmaceutical Company, Tokyo, Japan
}

\begin{abstract}
Background. It is likely that there are some discrepancies in the safety and efficacy results for anticancer agents between those shown in registration studies for approval and those shown in clinical practice after market release. The aim of this survey was to confirm the safety and efficacy of S-1 for advanced gastric cancer after market release.

Methods. After the approval of S-1 in 1999, all patients had to be registered with the manufacturer for a post-marketing survey, according to the government recommendation. All patients were monitored for safety and survival. The data for all registered patients were updated 1 year after each registration.

Results. During this survey, a total of 4177 patients with advanced gastric cancer were registered. The incidences of all adverse events and of grade 3 or worse adverse events in the 3808 patients evaluable for safety were $74.3 \%$ and $25.0 \%$, respectively. In patients with lower creatinine clearance at baseline, the incidences of adverse reactions were higher for all grades combined, as well as for grades 3 or worse. There were $90(2.4 \%)$ early deaths (within 30 days of the initiation of the treatment) and $5(0.1 \%)$ deaths possibly related to the treatment. The median survival time and the 1-year survival rate for all patients evaluable for efficacy $(n=3801)$ were 8.3 months (95\% confidence interval $[\mathrm{CI}], 8.0-8.6$ months) and $33.3 \%$ (95\% CI, 31.8-34.9\%), respectively.

Conclusion. This nationwide survey confirmed that the safety and efficacy profiles of S-1 were similar to those seen in the registration study. These results have proven the utility of this post-marketing survey in assessing the reproducibility of the safety and efficacy results obtained from prior clinical studies.
\end{abstract}

Key words Gastric cancer $\cdot S-1 \cdot$ Post-marketing survey

Offprint requests to: A. Ohtsu

Received: July 15, 2004 / Accepted: September 16, 2004

\section{Introduction}

S-1 is a novel oral fluoropyrimidine agent that exploits the biochemical modulation of 5-fluorouracil (FU) pharmacokinetics. S-1 contains tegafur (FT), gimestat (CDHP), and otastat potassium (Oxo) at a molar ratio of $1: 0.4: 1$. This agent was initially developed by Taiho Pharmaceutical Company, Tokyo [1], for gastric cancer in Japan. In the two phase II registration studies, this agent demonstrated excellent activity for gastric cancer, with response rates of $49 \%(25 / 51)$ and $40 \%(20 / 50)$, respectively $[2,3]$. The toxicity profile of this agent was mild: less than a $10 \%$ incidence of grade 3 or 4 adverse events and no treatment-related deaths. Based on these results, the agent was approved for the treatment of gastric cancer by the Ministry of Health, Labor, and Welfare (MHLW) of Japan, in 1999.

There have been several scandals in investigational trials of new drugs in Japan. In the development of irinotecan (CPT-11), which was first developed in Japan, there were some treatment-related deaths during the registration study: 20 of 477 patients died of toxicity during phase I and II clinical trials carried out between 1986 and 1990. This was not revealed in clinical trial publications or by MHLW staff, but was exposed instead by a newspaper, in 1993 [4]. These issues prompted the MHLW to adopt new "Good Clinical Practice (GCP)" guidelines for new drug approval, in 1997. Although these guidelines require strict safety monitoring with source document verifications and audit by the company, new anticancer agents are approved based on the results of two independent phase II studies. Because limitations on obtaining safety information are inevitable before approval, the MHLW recommended the use of nationwide post-marketing surveys for safety monitoring after the market release of a new drug. In accordance with the recommendations of the MHLW, Taiho Pharmaceutical Company conducted the present survey, with the goal of enrolling up 
to 3000 patients in Japan. Before starting the postmarketing survey, the company contracted with a total of 757 participating institutions in Japan. This agent was not provided to any non-participating institution until completion of this survey.

\section{Patients and methods}

\section{Contract with institutions}

For the company to contract with an institution for this survey, the following requirements had to be met: availability of at least one attending physician who had sufficient experience of chemotherapy and who could undertake monitoring of patients at least once in 2 weeks, and the institution had to have the capability for immediate and adequate treatment of potential serious adverse events. All patients were monitored by the company, with a case report form filled out by each physician.

\section{Registration}

To promote the safe use of S-1, the company prepared guidelines for appropriate use, based on the previous registration studies. The guidelines ("appropriate-use" criteria) consisted of the following requirements for patients: having unresectable or recurrent gastric cancer; Eastern Cooperative Oncology Group (ECOG) performance status (PS) of 2 or better; WBC of 3500$12000 / \mu l$; neutrocytes, 2000/ $\mu$ l or more; hemoglobin, $9.0 \mathrm{~g} / \mathrm{dl}$ or more; platelets, $100000 / \mu \mathrm{l}$ or more; and total bilirubin, aspartate aminotransferase (AST), and alanine aminotransferase (ALT) within two times the upper limit, and serum creatinine within the normal upper limit. For patients who failed some of the above criteria, administration of this agent was allowed, under careful observation, if the abnormal findings met the following criteria ("careful-use" criteria): ECOG PS within 3;

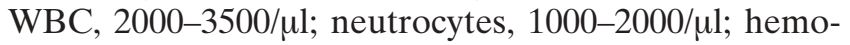
globin, $8.0-9.0 \mathrm{~g} / \mathrm{dl}$; platelets, $75000-100000 / \mu \mathrm{l}$; total bilirubin, two times the upper limit to $3.0 \mathrm{mg} / \mathrm{dl}$; AST and ALT, two times the upper limit to $150 \mathrm{IU} / 1$, and serum creatinine, normal upper limit to $1.5 \mathrm{mg} / \mathrm{dl}$.

All patients were required to give their informed consent and had to receive this agent as single-agent therapy. The patients were registered on a registration form completed by the physicians and the forms were sent to Taiho Pharmaceutical Company via facsimile. After confirmation of the registration, the company provided the agent to be given to the patients.

\section{Treatment}

S-1 was administered according to the treatment schedule for the registration studies. The initial doses were assigned on the basis of body surface area (BSA), as follows: $80 \mathrm{mg} /$ day for BSA less than $1.25 \mathrm{~m}^{2} ; 100 \mathrm{mg} /$ day for BSA less than $1.5 \mathrm{~m}^{2}$, and $120 \mathrm{mg} /$ day for BSA of $1.5 \mathrm{~m}^{2}$ or more. The treatment schedule consisted of 28 consecutive days of twice-daily administration (after breakfast and dinner) followed by a 2-week rest. This schedule was repeated every 6 weeks until the occurrence of disease progression, unacceptable toxicities, or patient's refusal. Modifications of dose and schedule were carried out by each physician according to the procedures in the previous registration studies, but without being regulated by the company.

\section{Monitoring}

Site-visit monitoring by the company was conducted regularly once a month. The case report forms were also collected monthly and were analyzed immediately by the company, followed by a report sent to the MHLW, once every 6 months. Adverse events were graded according to the toxicity criteria of the Japan Society for Cancer Therapy [5], which were modified from the criteria devised by the WHO. Serious or unexpected events were monitored throughout all administered courses, while other events were evaluated during the first two courses.

\section{Safety analysis}

Because this survey was carried out after market release, it included a few patients who were ineligible according to the "appropriate-use" guidelines mentioned in the "Registration" section, who were, however, administered the agent at the discretion of physicians. Although these patients seemed to be inappropriate for any chemotherapy, the company could not dissuade such inappropriate use in general settings. For safety analysis, all patients registered were classified into three groups according to the patients' baseline background: an "appropriate group", whose baseline data also met the eligibility criteria for the registration studies; a "careful-use" group, who needed careful observation as a condition of receiving the chemotherapy; and an "inappropriate" group, consisting of the remaining patients who failed the careful-use criteria. Baseline creatinine clearance was calculated, using the Cockcroft-Gault formula [6], for the precise evaluation of safety in patients with renal impairment.

\section{Survival updating}

The survival data of all patients registered were updated at 1 year after each registration and compared with the corresponding values in the previous phase II studies before approval; namely, the median survival time 
(MST) of 8.0 months and 1-year survival rate of $36.6 \%$ $[2,3]$.

\section{Statistics}

Cox proportional hazard analysis was employed to determine correlations between patients' baseline background and the incidence of all toxicities as well as the incidence of observed toxicities worse than or equal to grade 3. Patients were categorized into two groups by their eligibility status at baseline: "appropriate" group and a combination of the "careful-use" + "inappropriate" groups. Survival time was calculated from the initial date of the first course to the date of death, or the last confirmation of survival, using the Kaplan-Meier method.

\section{Results}

\section{Patient characteristics}

During the period between March 1999 and March 2000, a total of 4177 patients were registered for this survey from 757 institutions all over Japan. Of the 4177 patients, 286 did not actually receive the study agent, and 62 patients received S- 1 administered outside the conditions of the contract between the company and the institution. There were also 12 double registrations and 9 patients whose case reports were not returned by their respective institutions, leaving a total of 3808 patients evaluable for safety. Another 7 patients in whom the study agent was administered for cancers other than gastric cancer were excluded from the efficacy analysis. Baseline patient characteristics are shown in Table 1. Although most of the patients had a good PS, of 0 or 1 , at baseline, $19(0.5 \%)$ patients had a PS of 3 or 4 . The median age of the patients was 63 years, ranging from 18 to 92 years; $2.7 \%$ of the patients were 80 years or older. Two-thirds of the patients had a history of prior gastrectomy, and approximately $60 \%$ of the patients had received prior chemotherapy, mostly consisting of fluorouracil-based regimens. There were $2778(73 \%), 909(24 \%)$, and $121(3 \%)$ patients in the appropriate, careful-use, and inappropriate groups, respectively.

The proportions of patients who were administered at the approved standard doses were: $80 \mathrm{mg} /$ day for $90.5 \%$ of the patients with BSA less than $1.25 \mathrm{~m}^{2}$; $100 \mathrm{mg} /$ day for $79.1 \%$ of the patients with BSA of 1.25 $1.5 \mathrm{~m}^{2}$, and $120 \mathrm{mg} /$ day for $65.8 \%$ of the patients with BSA more than $1.5 \mathrm{~m}^{2}$. Most of the remaining patients were treated at reduced doses, usually one dose level down. The total number of courses administered ranged from 1 to 22 , with the median being 2; $1020(26.8 \%)$ and
Table 1. Patient characteristics

\begin{tabular}{|c|c|c|}
\hline Characteristic & & No. of patients \\
\hline Total & & 3808 \\
\hline Sex & $\begin{array}{l}\text { Male } \\
\text { Female }\end{array}$ & $\begin{array}{l}2661 \\
1147\end{array}$ \\
\hline Age (years) & $\begin{array}{l}<65 \\
\geqq 65 \\
\text { Median } \\
\text { Range }\end{array}$ & $\begin{array}{r}2158 \\
1650 \\
63 \\
18-92\end{array}$ \\
\hline $\begin{array}{l}\text { ECOG performance } \\
\text { status scale }\end{array}$ & $\begin{array}{l}0 \\
1 \\
2 \\
3,4\end{array}$ & $\begin{array}{r}2297 \\
1220 \\
272 \\
19\end{array}$ \\
\hline Prior chemotherapy ${ }^{\mathrm{a}}$ & $\begin{array}{l}\text { No } \\
\text { Yes }\end{array}$ & $\begin{array}{l}1542 \\
2253\end{array}$ \\
\hline $\begin{array}{l}\text { Renal function }{ }^{\mathrm{b}} \\
\quad \text { (by creatinine) }\end{array}$ & $\begin{array}{l}\text { Normal } \\
\text { High }(>\text { ULN })\end{array}$ & $\begin{array}{r}3560 \\
179\end{array}$ \\
\hline $\begin{array}{l}\text { Initial dosage } \\
(\mathrm{mg} \cdot \text { day-1) }\end{array}$ & $\begin{array}{l}80 \\
100 \\
120 \\
\text { Others }\end{array}$ & $\begin{array}{r}675 \\
1968 \\
1074 \\
91\end{array}$ \\
\hline
\end{tabular}

ULN, upper limit of normal range

${ }^{a} 13$ unknown cases were excluded

' 69 unknown cases were excluded

1089 (28.6\%) patients discontinued the treatment during the first and second courses, respectively.

\section{Safety profile}

The incidences of all adverse events and the incidence of grade 3 or worse events during the first and second courses were $74.3 \%$ and $25.0 \%$, respectively (Table 2 ). Seventy-seven percent of the adverse events occurred during the first course of the treatment. Major toxicities were leukocytopenia, anorexia, and nausea/vomiting; they were generally mild, and grade 3 or 4 incidences were less than $10 \%$. Grade 3 or 4 diarrhea was also infrequent, with an incidence of $2.0 \%$.

Regarding the eligibility status at baseline, the incidences of grade 3 or 4 leukopenia and neutropenia were higher in the careful-use + inappropriate groups $(P=0.0001$; Table 3$)$. Similar tendencies were seen for anemia, thrombocytopenia, gastrointestinal toxicities (nausea/vomiting/anorexia), and fatigue. Based on the case reports, the median time to the worst toxic events was 22 days for hematological toxicities and 15 days for diarrhea and stomatitis, with a median recovery time from these toxicities of around 2 weeks.

There were $90(2.4 \%)$ early deaths (within 30 days of the initiation of the treatment), though these were mostly related to disease progression. Overall, $5(0.1 \%)$ deaths were possibly related to the treatment: 2 , patients died of serious thrombocytopenia causing cerebral hemorrhage and disseminated intravascular 
Table 2. Toxicity profile

\begin{tabular}{lcc}
\hline & \multicolumn{2}{c}{ Incidence $(n=3808)$} \\
\cline { 2 - 3 } Toxicity & All adverse events & $\geqq$ Grade 3 events \\
\hline Leukopenia & $26.0 \%(991)$ & $2.6 \%(99)$ \\
Neutropenia & $21.3 \%(810)$ & $6.1 \%(231)$ \\
Anemia & $15.7 \%(597)$ & $4.6 \%(176)$ \\
Hemoglobin decreased & $9.0 \%(343)$ & $1.6 \%(60)$ \\
Red blood cell count decreased & $8.1 \%(310)$ & $1.9 \%(73)$ \\
Hematocrit decreased & $5.2 \%(199)$ & $0.8 \%(29)$ \\
Thrombocytopenia & $8.3 \%(317)$ & $1.5 \%(59)$ \\
Aspartate aminotransferase increased & $5.2 \%(198)$ & $0.6 \%(22)$ \\
Alanine aminotransferase increased & $4.6 \%(175)$ & $0.4 \%(16)$ \\
Nausea / Vomiting & $19.3 \%(734)$ & $2.2 \%(85)$ \\
Anorexia & $26.4 \%(1004)$ & $5.9 \%(226)$ \\
Fatigue & $17.5 \%(666)$ & $3.5 \%(132)$ \\
Diarrhea & $16.5 \%(629)$ & $2.0 \%(77)$ \\
Stomatitis & $12.5 \%(476)$ & $1.2 \%(46)$ \\
Pigmentation & $14.6 \%(557)$ & $1.1 \%(43)$ \\
Rash & $8.4 \%(318)$ & $0.9 \%(34)$ \\
Overall & $74.3 \%(2831)$ & $25.0 \%(952)$
\end{tabular}

Actual numbers of cases are shown in parentheses

Table 3. Incidence of toxicities in three patient groups classified by administration eligibility status

\begin{tabular}{|c|c|c|c|c|c|c|}
\hline \multirow[b]{2}{*}{ Toxicity } & & \multicolumn{3}{|c|}{$\begin{array}{c}\text { Incidence in patient groups according to } \\
\text { eligibility status }\end{array}$} & \multirow[b]{2}{*}{$\begin{array}{l}\text { Hazard ratio } \\
(95 \% \mathrm{CI})^{*}\end{array}$} & \multirow[b]{2}{*}{$P$ value* } \\
\hline & & $\begin{array}{l}\text { Appropriate } \\
(n=2778)\end{array}$ & $\begin{array}{c}\text { Careful-use } \\
(n=909)\end{array}$ & $\begin{array}{l}\text { Inappropriate } \\
\quad(n=121)\end{array}$ & & \\
\hline Leukopenia/Neutropenia & $\begin{array}{c}\text { All } \\
\geqq \text { Grade } 3\end{array}$ & $\begin{array}{r}29.7 \% \\
5.5 \%\end{array}$ & $\begin{array}{l}32.5 \% \\
11.9 \%\end{array}$ & $\begin{array}{l}32.2 \% \\
10.7 \%\end{array}$ & $\begin{array}{c}2.314 \\
(1.823-2.938)\end{array}$ & $P=0.0001$ \\
\hline Anemia & $\begin{array}{c}\text { All } \\
\geqq \text { Grade } 3\end{array}$ & $\begin{array}{r}25.5 \% \\
5.2 \%\end{array}$ & $\begin{array}{l}28.3 \% \\
11.0 \%\end{array}$ & $\begin{array}{r}24.8 \% \\
9.9 \%\end{array}$ & $\begin{array}{c}2.325 \\
(1.816-2.977)\end{array}$ & $P=0.0001$ \\
\hline Thrombocytopenia & $\begin{array}{c}\text { All } \\
\geqq \text { Grade } 3\end{array}$ & $\begin{array}{l}7.5 \% \\
1.3 \%\end{array}$ & $\begin{array}{r}10.7 \% \\
2.2 \%\end{array}$ & $\begin{array}{l}9.1 \% \\
2.5 \%\end{array}$ & $\begin{array}{c}1.824 \\
(1.081-3.079)\end{array}$ & $P=0.0243$ \\
\hline $\begin{array}{l}\text { Aspartate/alanine aminotransferase } \\
\text { increased blood bilirubin increased }\end{array}$ & $\begin{array}{c}\text { All } \\
\geqq \text { Grade } 3\end{array}$ & $\begin{array}{r}12.3 \% \\
1.7 \%\end{array}$ & $\begin{array}{r}10.1 \% \\
2.2 \%\end{array}$ & $\begin{array}{l}4.1 \% \\
1.7 \%\end{array}$ & $\begin{array}{c}1.352 \\
(0.815-2.244)\end{array}$ & $P=0.2428$ \\
\hline Nausea, vomiting, anorexia & $\begin{array}{c}\text { All } \\
\geqq \text { Grade } 3\end{array}$ & $\begin{array}{r}31.5 \% \\
5.9 \%\end{array}$ & $\begin{array}{r}33.2 \% \\
7.6 \%\end{array}$ & $\begin{array}{l}34.7 \% \\
10.7 \%\end{array}$ & $\begin{array}{c}1.42 \\
(1.089-1.852)\end{array}$ & $P=0.0095$ \\
\hline Fatigue & $\begin{array}{c}\text { All } \\
\geqq \text { Grade } 3\end{array}$ & $\begin{array}{r}16.3 \% \\
3.0 \%\end{array}$ & $\begin{array}{r}20.2 \% \\
4.4 \%\end{array}$ & $\begin{array}{r}23.1 \% \\
6.6 \%\end{array}$ & $\begin{array}{c}1.637 \\
(1.148-2.335)\end{array}$ & $P=0.0064$ \\
\hline Diarrhea & $\begin{array}{c}\text { All } \\
\geqq \text { Grade } 3\end{array}$ & $\begin{array}{r}15.9 \% \\
1.9 \%\end{array}$ & $\begin{array}{r}17.9 \% \\
2.3 \%\end{array}$ & $\begin{array}{r}19.0 \% \\
2.5 \%\end{array}$ & $\begin{array}{c}1.276 \\
(0.788-2.067)\end{array}$ & $P=0.3219$ \\
\hline Stomatitis & $\begin{array}{c}\text { All } \\
\geqq \text { Grade } 3\end{array}$ & $\begin{array}{r}12.3 \% \\
1.2 \%\end{array}$ & $\begin{array}{r}13.4 \% \\
1.4 \%\end{array}$ & $\begin{array}{r}10.7 \% \\
0.8 \%\end{array}$ & $\begin{array}{c}1.225 \\
(0.654-2.296)\end{array}$ & $P=0.5269$ \\
\hline Pigmentation & $\begin{array}{c}\text { All } \\
\geqq \text { Grade } 3\end{array}$ & $\begin{array}{r}14.9 \% \\
1.1 \%\end{array}$ & $\begin{array}{r}13.6 \% \\
1.0 \%\end{array}$ & $\begin{array}{r}14.9 \% \\
3.3 \%\end{array}$ & $\begin{array}{c}1.225 \\
(0.639-2.348)\end{array}$ & $P=0.5417$ \\
\hline Rash & $\begin{array}{c}\text { All } \\
\geqq \text { Grade } 3\end{array}$ & $\begin{array}{l}8.4 \% \\
0.9 \%\end{array}$ & $\begin{array}{l}7.9 \% \\
0.7 \%\end{array}$ & $\begin{array}{l}9.9 \% \\
1.7 \%\end{array}$ & $\begin{array}{c}0.86 \\
(0.389-1.900)\end{array}$ & $P=0.7097$ \\
\hline
\end{tabular}

* Appropriate group vs careful-use and inappropriate groups

coagulopathy; 1 died of neutropenic sepsis; 1 died of hepatic failure; and 1 died of hyperglycemia with metabolic acidosis. Of these 5 patients, those patients who died of neutropenic sepsis and hyperglycemia were in the appropriate group; and the 2 patients who died of serious thrombocytopenia and the patient who died of hepatic failure were in the careful-use group.

The incidences of hematological toxicities (leukopenia, neutropenia, anemia thrombocytopenia) in relation to creatinine clearance, calculated using the Cockcroft- 
Table 4. Incidence of hematological toxicities in four patient groups classified by creatinine clearance ${ }^{a}$

\begin{tabular}{|c|c|c|c|c|}
\hline \multirow{2}{*}{$\begin{array}{l}\text { Creatinine clearance } \\
(\mathrm{ml} / \mathrm{min})\end{array}$} & \multicolumn{2}{|c|}{$\begin{array}{l}\text { Patients administered at } \\
\text { standard initial dose }\end{array}$} & \multicolumn{2}{|c|}{$\begin{array}{l}\text { Patients administered at } \\
\text { reduced initial dose }\end{array}$} \\
\hline & Overall incidence & $\geqq$ Grade 3 & Overall incidence & $\geqq$ Grade 3 \\
\hline$<30$ & $70.0 \%(14 / 20)$ & $45.0 \%(9 / 20)$ & $41.2 \%(7 / 17)$ & $23.5 \%(4 / 17)$ \\
\hline$\geqq 30$ to $<50$ & $56.4 \%(206 / 365)$ & $23.3 \%(85 / 365)$ & $45.5 \%(70 / 154)$ & $18.8 \%(29 / 154)$ \\
\hline$\geqq 50$ to $<80$ & $47.6 \%(640 / 1345)$ & $13.8 \%(185 / 1345)$ & $40.1 \%(173 / 431)$ & $12.1 \%(52 / 431)$ \\
\hline$\geqq 80$ & $40.7 \%(429 / 1054)$ & $9.2 \%(97 / 1054)$ & $36.3 \%(115 / 317)$ & $10.7 \%(34 / 317)$ \\
\hline
\end{tabular}

a Patients with unknown baseline creatinine level or who received inadequate dose were excluded from this analysis

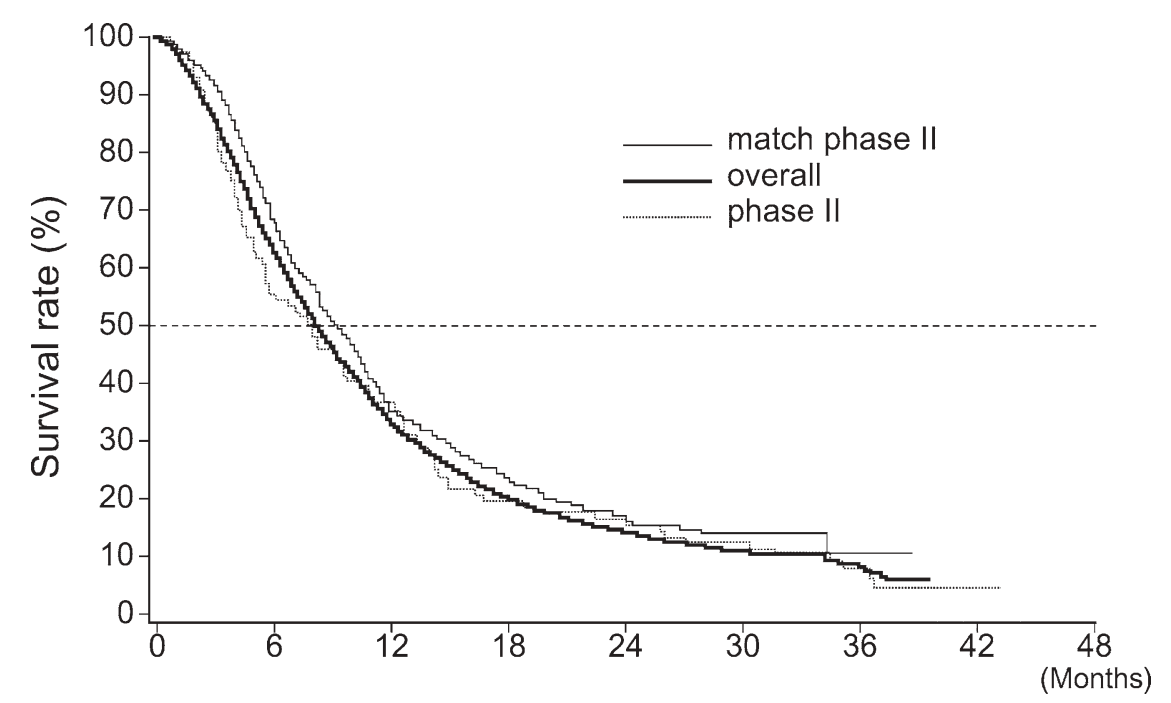

Fig. 1. Survival curves, for patients overall $(n=3801)$, for those with criteria that matched phase II criteria (match phase II; $n=483)$, and for patients in the original phase II study (phase II; $n=101$ )
Gault formula, are shown in Table 4. In the patients with lower creatinine clearance, the incidences of adverse reactions were higher for all grades combined, as well as for grades 3 or worse. Additionally, in the patients who initially received administration at a reduced dose, the incidence of adverse reactions was lower.

\section{Efficacy results}

For the efficacy analysis, $280(7.3 \%)$ of the 3801 patients suitable for the analysis were lost to follow up. The MST of these 3801 patients was 8.3 months (95\% confidence interval [CI], 8.0-8.6 months), and the 1-year survival rate was $33.3 \%(95 \% \mathrm{CI}, 31.8 \%-34.9 \%)$ (Fig. 1). Among these 3801 patients, 1540 patients had had no prior chemotherapy and 483 of these patients had baseline data which met the eligibility criteria of the prior registration phase II studies (age, 20-74 years; PS, 2 or better; WBC, 4000-12000/ul; hemoglobin, $>9.0 \mathrm{~g} /$ $\mathrm{dl}$; platelets, $>100000 / \mu \mathrm{l}$; total bilirubin, $\leqq 1.5 \mathrm{mg} / \mathrm{dl}$; AST and ALT, $100 \mathrm{IU} / \mathrm{l}$; alkaline phosphatase [ALP], within two times the upper limit; serum creatinine, within the normal upper limit; and no history of prior chemotherapy $[2,3])$. The MST and 1-year survival rate of these 483 patients were 9.3 months (95\% CI, 8.410.3 months) and $36.1 \%$ (95\% CI, 31.7\%-40.6\%), respectively.

\section{Discussion}

There have been several scandals around new drug approvals in Japan. Eighteen people died as a result of the combined use of sorivudine (an anti-herpes drug that completely inhibits dihydropyrimidine dehydrogenase) with fluorouracil-based anticancer drugs. Twenty of 477 patients died of toxicity during phase I and phase II registration studies of CPT-11, which was approved in 1994. These unfortunate results prompted the MHLW to change the Japanese drug approval system; new guidelines, "the Revised Good Clinical Practice", which recommended very strict safety monitoring during the registration studies, were adopted in 1997. In these guidelines, the MHLW requires two independent phase II studies for new drug approval, while the applicant is required to perform a post-marketing survey and studies to demonstrate the clinical benefit of the approved drug. In accordance with the Japanese approval system, 
the company (Taiho Pharmaceutical Company) sponsored two independent phase II studies of S-1, which demonstrated high activity for gastric cancer, and achieved an accelerated approval in Japan. Then, as recommended by the MHLW, the company conducted a nationwide post-marketing survey in a strict manner to prevent the improper use of this agent from causing serious toxicities in general use.

Limitations are inevitable in obtaining information (particularly regarding the safety profile) for a new agent before its approval. In the Japanese system, the safety data of this new agent were obtained from only about 100 patients before marketing. In addition, only $31 \%(483 / 1540)$ of the chemo-naive patients in this present survey met the eligibility criteria of the prior registration study. Considering these limitations, it seems essential to keep the introduction of this agent under careful survey. Discrepancies in safety profiles are likely to occur between clinical studies and general use, particularly when the agent is indicated for gastric cancer. There are major differences in patient populations between these two settings. Although patients with peritoneal dissemination constitute a major proportion of gastric cancer patients, they are usually excluded as candidates for phase II studies because of difficulties in measuring the size of their metastatic lesions. These patients also have serious associated complications, such as bowel obstruction, hydronephrosis, and ascites, due to the peritoneal dissemination; these undesirable conditions are likely to delay the elimination of pharmacological components and may cause serious toxicities. Additionally, there are only a limited number of chemotherapy experts in Japan; the number of medical oncologists is still small in this country. Therefore, the use of newly approved agents, particularly for gastric cancer, should be carefully monitored under survey by the pharmaceutical company and the MHLW.

The overall incidences of adverse events in the present survey and in the phase II studies were $74.3 \%$ and $75.2 \%$, respectively $[2,3]$. These results suggest that the power of the present post-marketing survey was similar to that of the phase II studies. On the other hand, the incidences of adverse events of grade 3 or worse were $25.0 \%$ and $14.9 \%$, respectively. A possible cause of this discrepancy was the exclusion of patients potentially in the careful-use or inappropriate groups from the clinical studies, which rejected patients with a PS of 3 or WBC of less than 3500/ $\mu$ l. This interpretation fits well with the higher incidences of grade 3 or worse hematological toxicities in the careful-use and inappropriate groups than in the appropriate group in the present study. Another compromising factor could be impaired renal function; the incidences of grade 3 or worse hematological toxicities were also higher in the low-creatinine-clearance group. CDHP, a component of S-1 that sustains the concentration of tegafur-derived 5FU by inhibiting dihydropyrimidine dehydrogenase, is known to be eliminated by renal excretion $[7,8]$. Therefore, S-1 should be particularly carefully administered in patients with impaired renal function, particularly in those with creatinine clearance of $50 \mathrm{ml} / \mathrm{min}$ or less.

As for the efficacy analyses, the MST and 1-year survival rate in the present survey were 8.3 months and $33.3 \%$, respectively. Although the present population included patients with a prior history of chemotherapy and those with peritoneal dissemination, these survival results were comparable to those obtained in the phase II studies, i.e., 8.0 months and $36.6 \%$, respectively. The efficacy of S-1 seen in the clinical studies was thus shown to translate into real clinical benefits. These results have proven the utility of this post-marketing survey in assessing the reproducibility of the efficacy results obtained from prior clinical studies.

Acknowledgments We are grateful to Drs. M. Fukushima and C. Hamada for their kind advice. Our gratitude is also extended to the physicians and institutions who participated in the present survey. This survey was supported by Taiho Pharmaceutical Co Ltd, Tokyo.

\section{References}

1. Shirasaka T, Nakano K, Takechi T, Satake H, Uchida J, Fujioka A, et al. Antitumor activity of $1 \mathrm{M}$ tegafur-0.4M 5-chloro-2,4dihydroxypyridine-1 $\mathrm{M}$ potassium oxonate (S-1) against human colon carcinoma orthotopically implanted into nude rats. Cancer Res 1996;56:2602-6.

2. Sakata Y, Ohtsu A, Horikoshi N, Sugimachi K, Mitachi Y, Taguchi $\mathrm{T}$. Late phase II study of novel oral fluoropyrimidine anticancer drug S-1 (1 M tegafur-0.4 M gimestat- $1 \mathrm{M}$ otastat potassium) in advanced gastric cancer patients. Eur J Cancer 1998;34:1715-20.

3. Koizumi W, Kurihara M, Nakano S, Hasegawa K. Phase II study of S-1, a novel oral derivative of 5-fluorouracil, in advanced gastric cancer. Oncology 2000;58:191-7.

4. Fukushima M. Clinical trials in Japan. Nature Medicine 1995;1:1213.

5. Evaluation Criteria Committee of the Japan Society for Cancer Therapy. Revision of toxicity criteria. J Jpn Soc Cancer Ther 1997;32:61-5.

6. Cockcroft DW, Gault MH. Prediction of clearance from serum creatinine. Nephron 1976;16:31-41.

7. Tatsumi K, Fukushima M, Shirasaka T, Fujii S. Inhibitory effects of pyrimidine, barbituric acid and pyridine derivatives on 5fluorouracil degradation in rat liver extracts. Jpn J Cancer Res 1987;78:748-55.

8. Hirata K, Horikoshi N, Aiba K, Okazaki M, Denno R, Sasaki K, et al. Pharmacokinetic study of S-1, a novel oral fluorouracil antitumor drug. Clin Cancer Res 2000;5:2000-5. 